\title{
Fluorescence histochemical demonstration of a relationship between adrenergic nerves and cells containing actin and myosin in the rat ovary, with special reference to the follicle wall
}

\author{
B. Walles*, Ute Gröschel-Stewart†, Ch. Owman†, N.-O. Sjöberg§, \\ and $\mathrm{K}$. Unsicker $\Psi$
}

Departments of *Zoology, $\ddagger$ Histology, and §Obstetrics and Gynecology, University of Lund, S-223 62 Lund, Sweden; †Department of Zoology, Technische Hochschule Darmstadt, D-61 Darmstadt; and IDepartment of Anatomy, University of Kiel, D-2300 Kiel, West Germany

\begin{abstract}
Summary. Contractile proteins (actin and myosin detected by immunohistochemistry) were present in elongated cells forming concentric layers in the theca externa of Graafian follicles and around corpora lutea. Immunofluorescent cells were also found in the ovarian stroma. Study of adrenergic nerve fibres by the glyoxylic acid technique showed numerous branches in between and in close association with the contractile cells.
\end{abstract}

It has long been known that the wall of the Graafian follicle has contractile properties (Guttmacher \& Guttmacher, 1921) and numerous histological studies have been carried out to determine the structural substrate for these contractions. However, the histological staining techniques available have not provided sufficient specificity or selectivity for an unequivocal characterization and description of ovarian smooth muscle. The existence of non-vascular smooth musculature in the mammalian ovary has, therefore, been a matter of controversy (see Burden, 1973). It was hoped that the question could be answered by electron microscope studies, first applied to this problem by O'Shea (1970) and Osvaldo-Decima (1970). However, smooth muscle cells in the ovary are not as easily definable as in other peripheral organs: they cannot, for example, always be clearly distinguished from fibroblasts, and transition forms between these and ovarian smooth muscle-like cells seem to be a characteristic feature (O'Shea, 1970; Burden, 1972). The immunohistochemical demonstration of actin and myosin in cells with a perifollicular localization (Amsterdam, Lindner \& Gröschel-Stewart, 1977) has recently provided proof for the existence in the mammalian ovary of non-vascular contractile elements in amounts sufficient to explain the follicular contractile properties. The problem has received increasing interest during the past decade because of the possible involvement of ovarian and follicular contractility in the ovulation process (see Owman, Sjöberg, Wallach, Walles \& Wright, 1977 for review).

The motor activity of the follicle wall is influenced by sympathetic nerves, which are present in considerable number around the follicle. These effects can be mimicked by various sympathomimetic compounds, and they are mediated by alpha- and beta-adrenergic receptors (Owman, Sjöberg, Svensson \& Walles, 1975). The present study was undertaken to elucidate the relationship between follicular adrenergic nerves, visualized by glyoxylic acid histofluorescence, and cells in the theca externa containing contractile proteins, demonstrated by the indirect immunohistochemical technique.

\section{Methods}

Sexually mature Wistar rats of $200 \mathrm{~g}$ body weight were used. The ovaries were dissected out, frozen and sectioned in a cryostat at $-30^{\circ} \mathrm{C}$. Adrenergic nerves were visualized in $15 \mu \mathrm{m}$ thick sections by the glyoxylic acid technique (Lindvall \& Björklund, 1974) performed as described by de la Torre \& Surgeon (1976). Adjacent, $5 \mu \mathrm{m}$ thick sections were airodried for $1-2 \mathrm{~h}$ aśd incubafed for $30^{2} \mathrm{~min}_{\mathrm{V}}^{2} \mathrm{a}$ t 
room temperature with specific, $\gamma$-globulin-enriched rabbit antibodies and their corresponding controls as follows: (1) antiserum $(1 \mathrm{mg} / \mathrm{ml})$ raised against purified myosin from chicken gizzard smooth muscle, (2) antiserum (1-2 $\mathrm{mg} / \mathrm{ml})$ to actin purified from acetone-powder of chicken gizzard muscle and showing a single band on $10 \%$ sodium dodecyl sulphate-acrylamide gel electrophoresis which corresponds to a molecular weight of 42000 , (3) antibody to gizzard smooth muscle myosin previously adsorbed to chicken gizzard myosin, (4) the same antibody adsorbed to striated muscle (pectoralis) myosin, and (5) normal, non-immune rabbit $\gamma$-globulin. After washing, the sections were incubated for $30 \mathrm{~min}$ in a solution $(1 \mathrm{mg} / \mathrm{ml})$ of fluorescein-labelled immunoglobulin raised in sheep against rabbit. Further controls were incubated with this second antibody alone. Before mounting in a glycerol-0.1 M-glycine buffer $(7: 3 \mathrm{v} / \mathrm{v}), \mathrm{pH} 8 \cdot 6$, the sections were washed in phosphate-buffered

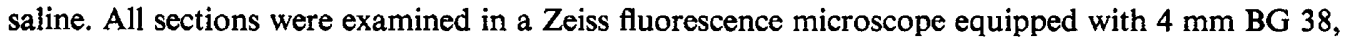
$2 \times \mathrm{KP} 420$ and K 530 filters. For further biochemical and technical details of the purity of the antigens used and the specificity of the antibody, including inhibition of specific biochemical functions of the antigen by the antibodies, see Amsterdam et al. (1977), Gröschel-Stewart, Schreiber, Mahlmeister \& Weber (1976), and Gröschel-Stewart, Ceurremans, Lehr, Mahlmeister \& Paar (1977).

\section{Results and Discussion}

Glyoxylic acid-treated sections revealed a well developed ovarian supply of delicate, green-fluorescent adrenergic nerve fibres with a beaded appearance characterizing the terminal part of the axon. Many of the nerves formed dense plexuses around blood vessels (Pl. 1, Fig. 1), whereas others ran isolated in the stroma without obvious relation to the vascular bed (PI. 1, Fig. 3). Several of the axon terminals were seen to enter the theca externa of follicles (PI. 2, Fig. 5) of various sizes and of corpora lutea. In the follicle wall, the fluorescent nerve fibres had an essentially meridional orientation. The ovarian adrenergic innervation was principally the same in all stages of the oestrous cycle (determined from vaginal smears examined by phase-contrast microscopy).

When ovarian sections were incubated with specific antibodies against smooth-muscle myosin and fluorescein-labelled anti- $\gamma$-globulin serum, an intense and discrete fluorescence was seen entirely surrounding the follicles (Pl. 1, Fig. 4). The fluorescent material was distributed in elongated cell elements or bands forming several concentric layers within the theca externa (PI. 2, Fig. 6). The layers of myosin-fluorescent cells were best developed in the walls of Graafian follicles and around corpora lutea, whereas thinner layers enclosed smaller follicles. Small groups of elongated immunofluorescent cells were also present in isolated or branching bundles in the ovarian stroma (PI. 1, Fig. 4). Intense myosin fluorescence was seen in the walls of the dense ovarian vascular plexus (P1. 1, Fig. 2). The relationship of the immunofluorescence to vascular or non-vascular cellular elements was determined by examination of the same area with phase-contrast optics.

\section{EXPLANATION OF PLATE 1}

Fig. 1. Glyoxylic acid histofluorescence in a rat ovary, showing the well developed adrenergic innervation of the blood vessels. A small artery is cut longitudinally and tangentially, and an adjacent arteriole is crosssectioned. $\times \mathbf{2 0 0}$.

Fig. 2. Adjacent section showing intense myosin immunoreactivity in the media layer of the blood vessels. $\times 200$.

Fig. 3. A section of a rat ovary at the cortico-medullary border treated to show the adrenergic nerves. A large follicle $(\mathrm{F})$ is seen with its innervation in the theca externa (arrows). The vascular nerve supply is prominent, and axon terminals also appear in the stroma. Glyoxylic acid technique. $\times 150$.

Fig. 4. Immunofluorescent localization of smooth muscle myosin in relation to a large antral follicle in another area of the same ovary as Fig. 3. The follicle is enclosed by intensely fluorescent myosin-containing cells collected in a well defined layer. Similar cells are present in strands within the stroma and in yessel walls. $\times 80$. 

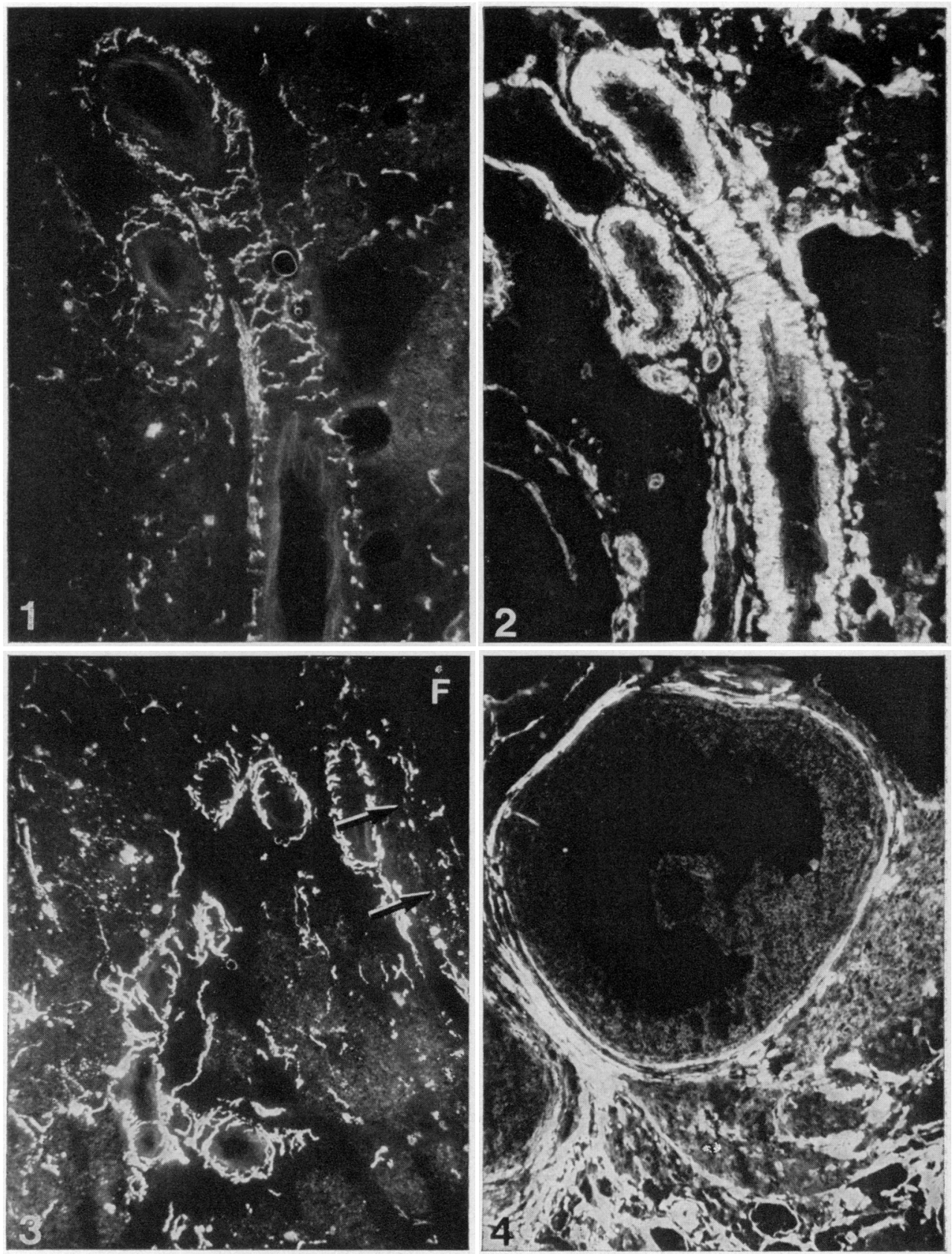


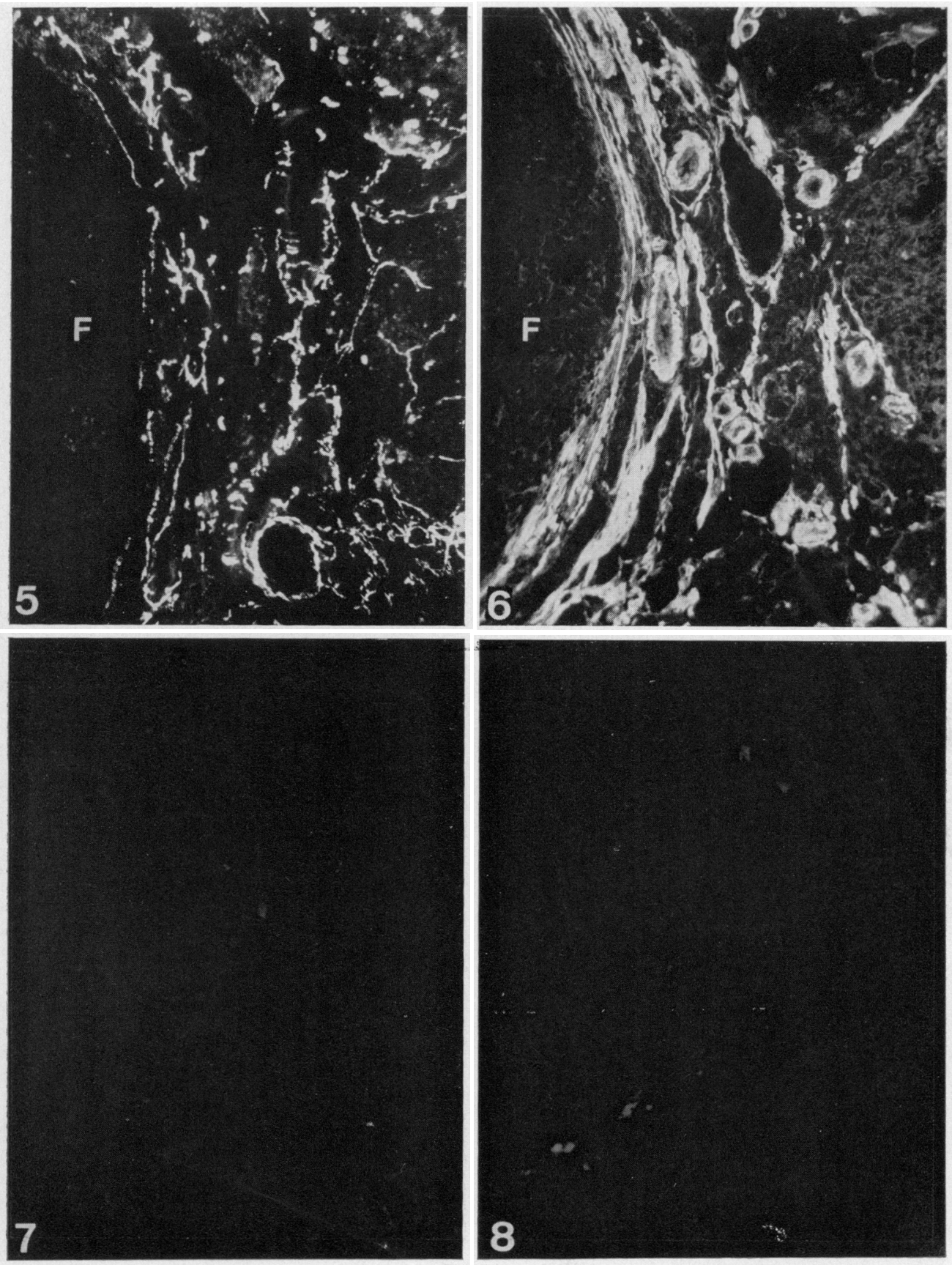


Incubation with myosin antibodies previously adsorbed to striated muscle myosin gave a more distinct fluorescence of similar intensity, and the greenish background fluorescence was reduced. Previous adsorption to smooth muscle myosin completely extinguished the fluorescence. Sections incubated with anti-actin showed a similar fluorescence distribution. The results of fluorescence microscopy with both types of antisera were similar to those presented by Amsterdam et al. (1977). No fluorescence occurred in sections incubated with non-immune control globulin (Pl. 2, Fig. 7) or in the presence of the fluorescein-labelled antiserum alone (PI. 2, Fig. 8). Although actin appears to be a component of many cell membranes, its presence without myosin is usually impossible to demonstrate by immunohistochemistry at the level of optical microscopy (one exception is the oolemma, as shown by Amsterdam et al., 1977). On the other hand, there is no evidence that myosin can occur in cells without actin. The presence of both actin and myosin in the cells is therefore used as the criterion for the contractile nature of the cells.

Examination of adjacent sections treated, on the one hand, for immunohistochemistry of contractile proteins and, on the other, for glyoxylic acid-induced demonstration of adrenergic nerves showed that the sympathetic axon terminals ran in between the contractile cells of the follicle wall and theca externa of the corpus luteum. It was evident, though, that not all of the actomyosincontaining cells were associated with fluorescent nerves. Comparison of consecutive sections also indicated that at least some of the non-vascular nerves in the ovarian stroma were related to the scattered immunofluorescent cells. A pronounced adrenergic innervation supplied the ovarian arteries and arterioles (Pl. 1, Fig. 1) in which the axon terminals formed a dense plexus superimposed on the immunofluorescent media layer (Pl. 1, Fig. 2).

Our results show that the rat follicular wall contains a system of non-vascular cells, which contain abundant smooth muscle actin and myosin. The system is sufficiently well developed to account for a contractile activity in the follicle wall. The association of these cells with adrenergic nerves corroborates the electron microscope observation of close contacts between adrenergic axon varicosities and cells having the ultrastructural characteristics of smooth muscle cells (Walles et al., 1975; Owman et al., 1975). Such contacts indicate a functional relationship of the nerve endings with the smooth muscle cells, which has been supported by experiments in which contractile activity has been induced in the follicular wall by electrical field stimulation of its adrenergic nerves (unpublished). The finding that not all of the contractile cells are associated with adrenergic nerve terminals suggests that the further spread of excitation from the innervated cells to other areas of the follicle wall is myogenic, and occurs via the junctional complexes present between individual myoid cells (Burden, 1972; Walles et al., 1975). Our results also support pharmacological observations that the capsule of the corpus luteum can exhibit motor activity under sympathomimetic influence (Okamura, Okazaki \& Nakajima, 1974). The presence of mixed populations of contractile cell elements in the ovarian stroma suggests that the spontaneous contractions, modifiable by catecholamines, in whole ovaries or composite preparations of ovarian tissue reflect a mixed activity of vascular and non-vascular smooth muscle cells (see Owman et al., 1977).

The work was supported by grants from the Ford Foundation (No. 680-0383 A), the World Health Organization (project No. 74066), and Deutsche Forschungsgemeinschaft (Ste 105/18 UN 34/4).

\section{EXPLANATION OF PLATE 2}

Adjacent sections of a rat ovary to show the relationship of adrenergic nerves and contractile cells in the theca externa of a large follicle (F), in adjacent stroma and in blood vessels.

Fig. 5. Adrenergic nerves are numerous, and several terminals enter the theca externa to run in a meridional fashion within the follicle wall. $\times 150$.

Fig. 6. Section incubated with antimyosin. The myosin-containing cells have a distribution closely resembling that of the adrenergic supply. $\times 150$.

Fig. 7. Control section incubated with non-immune rabbit $\gamma$-globulin, followed by the fluorescein-labelled antibody. $\times 150$.

Fig. 8. Section incubated with the fluorescein-labelled (second) antibody. Xip50. ientifica.com at 04/26/2023 01:16:29PM 


\section{References}

AMSTERDAM, A., LiNDNER, H.R. \& GrösCHEL-STEWART, U. (1977) Localization of actin and myosin in the rat oocyte and follicular wall by immunofluorescence. Anat. Rec. 187, 311-327.

Burden, H.W. (1972) Ultrastructural observations on ovarian perifollicular smooth muscle in the cat, guinea-pig, and rabbit. Am. J. Anat. 133, 125-142.

BURDEN, H.W. (1973) The distribution of smooth muscle in the cat ovary with a note on its adrenergic innervation. $J$. Morph. 140, 467-476.

DE la Torre, J.C. \& Surgeon, J.W. (1976) A methodological approach to rapid and sensitive monoamine histofiuorescence using a modified glyoxylic acid technique: the SPG method. Histochemistry 49, 81-93.

Gröschel-Stewart, U., Schreiber, J., Mahlmeister, C. \& Weber, C. (1976) Production of specific antibodies to contractile proteins, and their use in immunofluorescence microscopy. I. Antibodies to smooth and striated chicken myosins. Histochemistry 46, 229-236.

Gröschel-Stewart, U., Ceurremans, S., Lehr, I., Mahlmeister, C. \& PaAR, E. (1977) Production of specific antibodies to contractile proteins, and their use in immunofluorescence microscopy. II. Speciesspecific and species-non-specific antibodies to smooth and striated chicken muscle actin. Histochemistry 50, 271-279.

GutTMaCher, M.S. \& GutTMAChER, A.F. (1921) Morphological and physiological studies on the musculature of the mature Graafian follicle of the sow. Bull. Johns Hopkins Hosp. 32, 394-399.
Lindvall, O. \& BJöorklund, A. (1974) The glyoxylic acid fluorescence histochemical method: a detailed account of the methodology for the visualization of central catecholamine neurons. Histochemistry 39, 97-127.

Okamura, H., Okazaki, T. \& Nakajima, A. (1974) Effects of neurotransmitters and prostaglandins on human ovarian contractility. Obstet. Gynec. 44, $720-726$.

O'SHEA, J.D. (1970) An ultrastructural study of smooth muscle-like cells in the theca externa of ovarian follicles in the rat. Anat. Rec. 167, 127-140.

Osvaldo-Decima, L. (1970) Smooth muscle in the ovary of the rat and monkey. J. Ultrastruct. Res. 29, 218-237.

Owman, Ch., Suöberg, N.-O., Svensson, K.-G. \& Walles, B. (1975) Autonomic nerves mediating contractility in the human Graafian follicle. J. Reprod. Fert. 45, 553-556.

OWman, Ch., Suöberg, N.-O., Wallach, E.E., Walles, B. \& WRIGHT, K.H. (1977) Neuromuscular mechanisms of ovulation. In Human Ovulation: Mechanisms, Detection, Prediction and Regulation, in press. Ed. E. S. E. Hafez. Elsevier/North-Holland Biomedical Press, Amsterdam.

Walles, B., Edvinsson, L., Falck, B., OWman, Ch., Sjöberg, N.-O. \& Svensson, K.-G. (1975) Evidence for a neuromuscular mechanism involved in the contractility of the ovarian follicular wall: fluorescence and electron microscopy and effects of tyramine on follicle strips. Biol. Reprod. 12, 239-248.

Received 2 August 1977 